\title{
UTILIZANDO UMA REDE DE REFERÊNCIA VIRTUAL PARA DEFINIÇÃO DE PARÂMETROS QUE GARANTAM O DESEMPENHO DE SERVIÇOS E APLICAÇÕES
}

\author{
Dellano Lima Fernandes ${ }^{1}$ \\ Emerson de Jesus Duarte ${ }^{2}$ \\ Douglas D. J. de Macedo ${ }^{3}$
}

\begin{abstract}
RESUMO
O crescimento da internet como meio de comunicação, aliado a facilidade de acesso, proporcionou também o crescimento da disponibilização de serviços pela rede mundial de computadores. Atualmente, nota-se que grande parte das empresas entrega algum tipo de serviço para seus clientes ou colaboradores por meio de redes de longa distância ou pela Internet. O objetivo deste trabalho é comprovar os benefícios da utilização de uma rede de referência virtual pelas empresas, para definição de requisitos que garantam o desempenho dos serviços e aplicações. Foi implementado um modelo de rede de referência virtual utilizando ferramenta gratuita opensource para simulação de ambiente WAN, por meio do qual, foram testadas as funcionalidades da ferramenta e de alguns dos protocolos/serviços mais utilizados na internet. Os resultados dos testes permitiram constatar o quanto as características inerentes às redes de longa distância ou de melhor esforço como a Internet, impactam na comunicação de serviços/aplicações, comprovando a eficácia do uso da rede de referência virtual.
\end{abstract}

Palavras-chave: Redes. Simulação de WAN. Teste de Software.

\footnotetext{
${ }^{1}$ Tecnólogo; e-mail: dellanolf@gmail.com

${ }^{2}$ Especialista; e-mail: emerson.duarte@sc.senai.br

${ }^{3}$ Mestre; e-mail: douglas@sc.senai.br
} 


\section{INTRODUÇÃO}

O crescimento do uso da Internet como meio de comunicação, entretenimento e consumo nos últimos anos, aliado à facilidade de acesso fez com que o mercado on-line se tornasse atrativo para empresas privadas e órgãos do governo em todos os setores.

Os interesses nesse ramo são os mais variados: serviços, publicidade, informação, entretenimento, e-commerce. Além disso, as empresas têm aproveitado cada vez mais a rede mundial de computadores para diminuir custos de serviços básicos como telefonia. Contudo, um ponto importante que deve ser levado em consideração ao disponibilizar algum tipo de serviço pela Internet, é que alguns deles exigem uma capacidade diferenciada da conexão dos clientes, como maior largura de banda, menor atraso, baixa taxa de perda de pacotes; é o caso de aplicações multimídia (como o próprio VolP), streaming de vídeo, entre outras.

Uma pesquisa feita pela IPSOS/Reuters e divulgada por Gottfried (2012, p.1, tradução nossa) com trabalhadores do mundo todo, aponta que um em cada cinco deles (17\%) trabalha em home office (trabalho em casa), ou de qualquer lugar fora da empresa:

Esses funcionários, muitas vezes referidos como "teletrabalhadores", têm a flexibilidade de usar as telecomunicações (como telefone, e-mail, chat, online) para se comunicar com colegas em tempo real ou fazer o seu trabalho online a partir de um local remoto a qualquer momento que desejar geralmente fazendo login no seu local de trabalho - inclusive à noite e aos finais de semana. (GOTTFRIED, 2012, p.1, tradução nossa).

Quando se faz esse tipo de acesso de dentro da empresa, - Local Area Network (LAN - rede de área local) -, geralmente não há problemas de conexão, pois o tempo de resposta é praticamente nulo, já que se trata de dispositivos diretamente conectados em um espaço físico comum. Porém, quando esses mesmos serviços são acessados de localizações remotas, como um escritório do outro lado da cidade ou uma filial do outro lado do mundo, há vários fatores que podem afetar essa comunicação, como, por exemplo, latência, jitter, perda de pacotes, largura de banda disponível.

Constata-se, então, a necessidade de haver nas empresas que fornecem serviços online em geral, uma forma de verificar se o seu produto está preparado para o ambiente Wide Area Network (WAN - rede de área ampla), isto é, mediante testes, possibilitar a definição de requisitos mínimos de conexão, ou, a garantia de que o software - seja um site, serviço, ou jogo -, quando acessado por um usuário com uma conexão à Internet ruim ou instável, esteja preparado para isso.

Para a simulação destes tipos de cenários, as redes de referência virtuais foram criadas. A implementação de uma rede de referência virtual, possibilita testar tais serviços ou aplicativos sob diversos tipos de problemas de conexão de forma controlada, viabilizando a constatação das dificuldades, para que, posteriormente, sejam diminuídas, eliminadas ou apenas documentadas. 
Conforme se pode observar na Figura 1, a rede de referência virtual pode ser implementada utilizando-se de um simulador de WAN, que funciona como um gateway transparente, por meio do qual os servidores podem ser acessados com as mesmas dificuldades encontradas quando do acesso por redes de longa distância ou pela Internet.

Figura 1: Topologia Lógica da rede de referência virtual com simulador de WAN

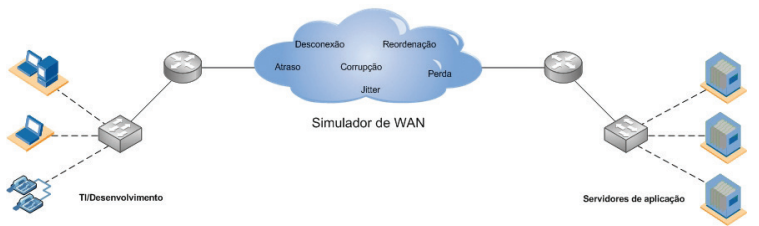

Fonte: Dos autores (2013)

Este trabalho tem como principal objetivo comprovar as vantagens da utilização de uma rede de referência virtual, para definição de requisitos que garantam o desempenho dos serviços e aplicações. Em um primeiro momento, são abordados os aspectos relativos ao desempenho nas redes de longa distância, visando à fundamentação teórica sobre os problemas que afetam este tipo de comunicação. Em um segundo momento, é tratada a implementação de uma rede de referência virtual, com intuito de comprovar o funcionamento do ambiente simulado, realizando testes com aplicações e cenários variados. Em seguida, são apresentados no artigo os resultados obtidos, com objetivo de constatar os benefícios da implementação da rede de referência virtual pelas empresas. Seguem então a conclusão e recomendações para trabalhos futuros.

\section{A QUESTÃO DO DESEMPENHO EM REDES DE LONGA DISTÂNCIA}

Em um cenário corporativo comum a comunicação de longa distância de uma empresa - entre suas filiais, parceiros, funcionários ou clientes remotos -, é afetada por três fatores principais: as tecnologias para acesso WAN utilizadas, o tipo de acesso à Internet utilizado pela empresa/clientes, e as características da própria Internet (Figura 2) (CISCO NET ACADEMY, 2012). Os problemas típicos relativos a desempenho enfrentados na rede WAN e na Internet são o foco deste trabalho. 


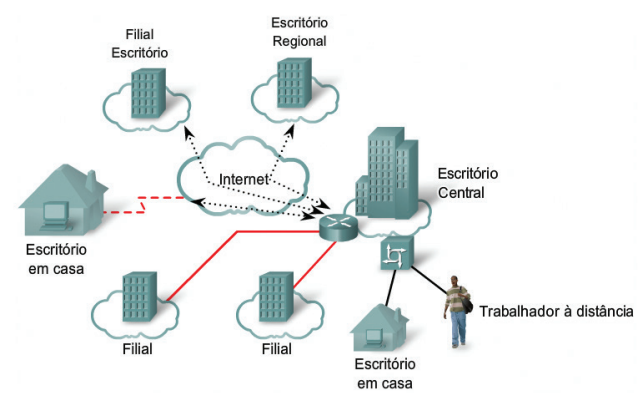

Fonte: Cisco Net Academy (2012)

A popularização da Internet deve-se em partes a sua arquitetura simples e descentralizada, na qual o serviço é de "melhor esforço", ou seja, não há controles ou garantias de que os dados atingirão o destino, tampouco prioridades para as aplicações com mais restrição em relação a desempenho (CISCO NET ACADEMY, 2012).

De uma forma geral, os usuários atuais de Internet já não usam somente os serviços tradicionais como Web, e-mail e transferência de arquivos, mas estão cada vez mais utilizando serviços que requerem um desempenho mais robusto da rede, como voz sobre IP (VoIP), streaming de vídeo, jogos on-line, compartilhamento de arquivos peer-to-peer, conforme Figura 3 (SCHULZE e MOCHALSKI, 2009, tradução nossa). Este, inclusive, é um dos maiores responsáveis pela deterioração do desempenho de outras aplicações na rede, devido à sua ampla utilização e consumo de banda; um estudo feito por Schulze e Mochalski (2009, tradução nossa) mostra que os aplicativos P2P (como Ares, BitTorrent, eDonkey, Gnutella) são responsáveis por mais da metade do tráfego no mundo, seguido de web, streaming e VoIP (FIGURA 3).

Figura 3: tráfego mundial por protocolo

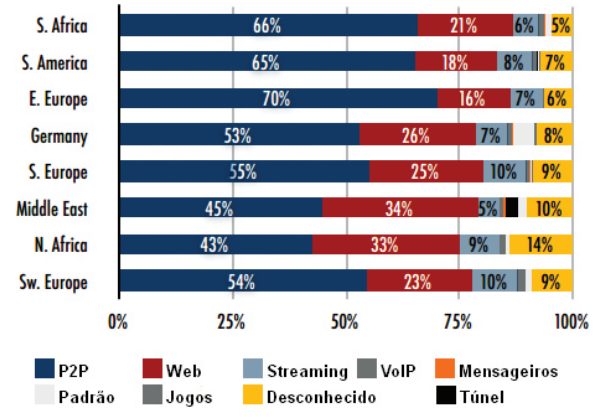

Fonte: Schulze e Mochalski (2009, tradução nossa) 
Alguns serviços como streaming de áudio e vídeo demandam uma conexão com atrasos constantes e reduzidos, além de largura de banda mínima para funcionar satisfatoriamente (Quadro 1). Lembrando que, nativamente, a Internet não oferece recursos para garantir tais requisitos, sendo necessária a utilização de técnicas de Quality of Service (QOS qualidade de serviço) para tal (COSTA, 2007).

Quadro 1: Exigências de comunicação para as mídias na Internet

\begin{tabular}{|l|l|l|l|}
\hline \multicolumn{1}{|c|}{ Recurso da rede } & \multicolumn{1}{c|}{ Dados } & \multicolumn{1}{c|}{ Voz } & Video \\
\hline Largura de banda necessária & Variável & Baixa a média & Alta \\
\hline Sensibilidade a perdas & Alta & Baixa & Baixa \\
\hline Sensibilidade a atrasos & Baixa & Alta & Alta \\
\hline Sensibilidade a variaçōes de atraso & Baixa & Alta & Alta \\
\hline
\end{tabular}

Fonte: Costa (2007)

As principais características que afetam a comunicação nas redes de longa distância, além de conceitos considerados importantes para este trabalho, serão tratadas a seguir.

\subsection{Largura de banda}

A largura de banda (bandwidth) corresponde à quantidade máxima de bits que pode ser transferida por um meio físico em um determinado período de tempo. Do ponto de vista da engenharia elétrica, a largura de banda (analógica) é uma quantidade medida em frequências $(\mathrm{Hz})$ - referentes à taxa máxima em que o hardware pode realizar mudanças de sinal -, já para quem trabalha com redes de computadores, a largura de banda (digital) corresponde à taxa de dados máxima de um canal, medida em bits por segundo (TANENBAUM, 2011).

A largura de banda não depende somente das características do meio físico, mas também, da tecnologia usada para colocar os dados nesse meio. Por exemplo, a largura de banda de um modem convencional está limitada a aproximadamente $56 \mathrm{Kbps}$ (kilobits por segundo) pelos fios de par trançado da rede de telefonia, porém, esse mesmo meio físico quando utilizado pela tecnologia xDSL (Digital Subscriber Line) pode transferir a taxas superiores a $10 \mathrm{Mbps}$, dependendo da tecnologia configurada e da última milha fornecida pelo provedor (TANEMBAUM, 2011).

Existem dois conceitos subjacentes à largura de banda: o throughput e o good put. 0 throughput (vazão) se refere à taxa de transmissão real de um determinado meio e é sempre menor do que a largura de banda em razão de diversos fatores, como quantidade de tráfego, tipo de tráfego, número de dispositivos utilizando a rede, entre outras.

O goodput refere-se aos dados aproveitáveis da camada de aplicação, ou seja, conforme Cisco Net Academy (2012) [...] é a medida dos dados úteis transferidos durante um determinado período e, portanto, é a medida que mais interessa aos usuários de 
rede". Enquanto o throughput mede a quantidade de bits, o goodput mede os dados que efetivamente importam para o funcionamento dos aplicativos envolvidos na comunicação.

O Quadro 2 foi adaptado da PixelBeat (2012) e mostra banda máxima de algumas tecnologias para comparação. Importante ressaltar que as medidas estão em Mbits/ segundo e, quando possível, o throughput efetivo foi mostrado em vez da capacidade física da tecnologia.

Quadro 2: Throughput de algumas tecnologias conhecidas

\begin{tabular}{|l|r|c|}
\hline \multicolumn{1}{|c|}{ Tecnologia } & Throughput (Mbps) & Obs \\
\hline 56K dialup & 0.043 & Fax/modem \\
\hline 2M ADSL & 1.761 & Assumindo overhead ATM+TCP de 14\% \\
\hline 12M ADSL2 & 10.568 & Assumindo overhead ATM+TCP de 14\% \\
\hline 24M ADSL2+ & 21.135 & Assumindo overhead ATM+TCP de 14\% \\
\hline Ethernet & 9.600 & Assumindo overhead TCP/IP de 4\% \\
\hline Fast Ethernet & 96.000 & Assumindo overhead TCP/IP de 4\% \\
\hline Gigabit Ethernet & 960.000 & Assumindo overhead TCP/IP de 4\% \\
\hline Bluetooth 2.0 & 2.080 & \\
\hline Wireless 802.11g & 24.800 & Muito variável \\
\hline Wireless 802.11n & 49.600 & \\
\hline DS1 & 1.544 & Também conhecido como T1 \\
\hline DS4 & 274.400 & Também conhecido como T4 \\
\hline E-1 & 2.048 & \\
\hline E-5 & 565.152 & \\
\hline OC-12 & 601.344 & Assumindo overhead Sonet de 3.3\% \\
\hline OC-48 & 2.405 .368 & Assumindo overhead Sonet de 3.3\% \\
\hline OC-192 & 9.669 .504 & Assumindo overhead Sonet de 3.3\% \\
\hline
\end{tabular}

Fonte: Adaptado de Pixelbeat (2012)

\subsection{Atraso ou latência}

Quando um pacote de dados trafega do transmissor ao receptor, este sofre diversos tipos de atraso em cada nó do caminho. A soma desses atrasos é chamada de atraso fima-fim ou latência da rede, que pode ser unidirecional (tempo que demora entre origem e destino), ou de ida-e-volta (tempo que demora para ir até o destino e retornar até a origem). Kurose e Ross (2010) apontam que os mais importantes desses atrasos são: atraso de processamento, de fila, de transmissão e de propagação (FIGURA 4), conforme detalhado adiante.

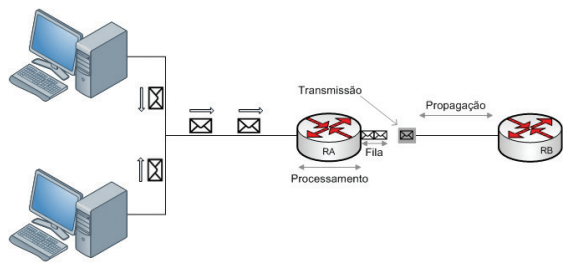

Fonte: Dos autores (2013) 
Conforme os dados trafegam pela rede, eles são processados por dispositivos como os roteadores, por exemplo, que precisam examinar o cabeçalho do pacote para tomar uma decisão sobre seu caminho, acrescentando um atraso chamado de atraso de processamento. Dispositivos finais da rede como computadores/servidores, também contribuem para esse atraso dependendo da capacidade de processamento, memória, mecanismos de cache, entre outros.

O atraso de fila ocorre quando há um congestionamento na interface de saída de um dispositivo, isto é, quando ele tem mais pacotes para enviar do que consegue lidar em um determinado intervalo de tempo. Assim, quando o pacote acaba de ser processado, precisa esperar que todos os pacotes da fila sejam enviados para que chegue a sua vez.

O atraso de transmissão refere-se à quantidade de tempo que o dispositivo leva para colocar todos os bits de um pacote no meio físico; já o tempo necessário para que o sinal ótico ou elétrico se propague pelo meio, saindo do transmissor até chegar ao receptor, é chamado de atraso de propagação e, geralmente, é proporcional à distância entre eles e às características do meio físico utilizado (KUROSE E ROSS, 2010).

\title{
2.3 Jitter
}

O jitter é a variação no atraso, ou seja, a variação do tempo que a mensagem leva para sair do transmissor e chegar ao receptor. As aplicações de tempo real como VolP ou streaming de vídeo são extremamente sensíveis a tal variação. Conforme exemplificou Comer (2007, p. 239), considerando o envio de voz através da rede:

\begin{abstract}
No lado do transmissor, o sinal analógico é digitalizado, e amostras digitais são emitidas a cada 125 microssegundos. As amostras são coletadas em pacotes ou células, que são transferidos através da rede. No lado do receptor, os valores digitais são extraídos e convertidos de volta em saídas analógicas. Se a rede tem jitter zero (ou seja, cada pacote leva exatamente o mesmo tempo para atravessar a rede), a saída de áudio será igual à entrada original. De outra maneira, a saída estará danificada.
\end{abstract}

Nesse caso, se o receptor ignorasse a variação do atraso e reproduzisse o áudio de acordo com os dados que estão chegando, a qualidade da voz seria prejudicada, tornando-se ininteligível; porém, existem técnicas para contornar o problema do jitter que não fazem parte do escopo deste trabalho, como, por exemplo, números de sequência, marcas de tempo, atraso de reprodução, uso de buffers (KUROSE e ROSS, 2010).

O jitter é um problema exclusivo de redes comutadas por pacotes (DAVIDSON e PETERS, 2000, tradução nossa). Além da variação de atraso, este implica também na entrega de pacotes fora de ordem, conforme Figura 5: 
Figura 5: Efeitos do Jitter na comunicação

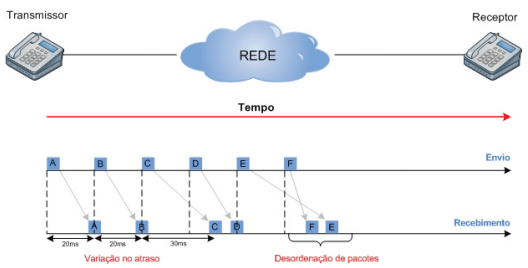

Fonte: Dos autores (2013)

\subsection{Perda de pacotes}

A perda de pacotes caracteriza-se quando pacotes que são enviados não conseguem alcançar o destino. A causa mais comum para este problema é o congestionamento da rede: ao trafegar do transmissor ao receptor, o pacote passa por buffers (filas) nos roteadores e, é possível que estes buffers estejam lotados e o roteador descarte esses pacotes (KUROSE e ROSS, 2010).

Assim como o jitter, esse problema é prejudicial principalmente a aplicações de fluxo de dados como VoIP e videoconferência, haja vista que geralmente utilizam protocolo UDP (User Datagram Protocol) (sem correções de erro, retransmissão) e, nesse caso, perder pacotes significa perder trechos de voz ou vídeo, o que impactará diretamente na qualidade da comunicação. Apesar disso, a perda de pacotes é um problema comum e esperado; portanto, existem limites aceitáveis dependendo da aplicação (DAVIDSON e PETERS, 2000, tradução nossa).

Por outro lado, quando se trata da transferência de um documento de texto, por exemplo, perder um pacote significa perder parte do arquivo, que pode ficar corrompido. Nesse caso, protocolos como o TCP podem cuidar da retransmissão desse pacote.

\section{IMPLEMENTANDO A REDE DE REFERÊNCIA VIRTUAL}

Para implementação da rede de referência virtual, foi utilizado um simulador de WAN. Por meio deste ambiente simulado, foram testados alguns cenários típicos de protocolos e serviços que utilizam comunicação via rede no modelo cliente-servidor, como SIP (Session Initiation Protocol - protocolo de inicialização de sessão) e videochamada. 
Para cada serviço testado, foram aplicadas diferentes configurações de rede, alterando fatores como largura de banda, atraso, jitter e perda de pacotes. Os resultados obtidos foram analisados e demonstrados em imagens/gráficos a fim de demonstrar o comportamento de cada serviço e/ou a percepção do usuário diante das configurações testadas.

\subsection{Cenário}

Para realização dos testes, foi utilizado um servidor físico rodando 3 máquinas virtuais, sendo:

a) cliente: máquina virtual configurada com aplicações para realização testes sobre os serviços fornecidos pelo Servidor, como: protocolo SIP e testes com alteração de parâmetros de rede;

b) simulador de WAN: máquina virtual configurada com software capaz de simular as características inerentes a uma rede de longa distância;

c) servidor: máquina virtual configurada com: servidor WEB, VoIP e demais ferramentas de rede.

A partir deste cenário, foram gerados testes de comunicação entre cliente e servidor, utilizando o simulador de WAN como intermediário (por meio de roteamento, conforme Figura 6). Em cada teste, foi registrado o comportamento da comunicação sem a ação do simulador, constatando as características normais da rede no laboratório e, posteriormente, foram registradas as mudanças ocorridas ao se aplicar determinadas características de WAN no simulador.

Figura 6: Topologia de rede lógica do laboratório

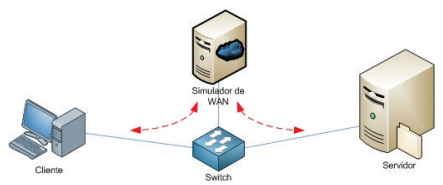

Fonte: Dos autores (2013) 


\subsection{Hardware Utilizado}

O Quadro 3 contém as informações de hardware do servidor físico e configurações das máquinas virtuais, além dos sistemas operacionais utilizados para os testes. Lembrando que, por se tratar de máquinas virtuais dentro de um mesmo servidor físico, a comunicação entre elas foi feita por meio do Virtual Switch, que se trata de um switch virtual lógico embutido dentro da estrutura do sistema de virtualização, neste caso, o VMware ESXI 4.1.

Quadro 3: Configurações das máquinas utilizadas nos testes

\begin{tabular}{|l|l|l|l|l|l|}
\hline & \multicolumn{1}{|c|}{ Processador } & Memória & \multicolumn{1}{|c|}{$\begin{array}{c}\text { Interface de } \\
\text { Rede/lP }\end{array}$} & $\begin{array}{c}\text { Sistema } \\
\text { Operacional }\end{array}$ & \multicolumn{1}{c|}{ Hard Disk } \\
\hline Servidor Fisico & $\begin{array}{l}\text { Intel Core I5 CPU 760 } \\
\text { @2.8GHz }\end{array}$ & 8GB RAM & $\begin{array}{l}\text { Broadcom NC30T } \\
\text { PCle GB Adap. }\end{array}$ & $\begin{array}{l}\text { Vmware ESXI } \\
4.1 .0\end{array}$ & 250GB 5400rpm \\
\hline Máq. Virtual - Cliente & $1 \mathrm{Vcpu}$ & 2GB RAM & $\begin{array}{l}\text { Vm Network E1000 } \\
(192.168 .0 .210)\end{array}$ & $\begin{array}{l}\text { Debian GNU Linux } \\
6.0\end{array}$ & 8GB Virt. Datastore \\
\hline Máq. Virtual - Servidor & $1 \mathrm{Vcpu}$ & 2GB RAM & $\begin{array}{l}\text { Vm Network E1000 } \\
(192.168 .0 .230)\end{array}$ & $\begin{array}{l}\text { Debian GNU Linux } \\
6.0\end{array}$ & 8GB Virt. Datastore \\
\hline Máq. Virtual - WANem & $1 \mathrm{Vcpu}$ & 2GB RAM & $\begin{array}{l}\text { Vm Network E1000 } \\
(192.168 .0 .201)\end{array}$ & Knoppix 5.3.1 & s/n (Live CD) \\
\hline
\end{tabular}

Fonte: Dos autores (2013)

Para os testes com videochamada, foram utilizados ainda dois IP Vídeo Phones, modelo Yeahlink VP530.

\subsection{Softwares Utilizados}

Para realização dos testes, optou-se pela utilização de softwares e sistemas operacionais livres/gratuitos devido ao baixo custo de implementação - somente operacional -, e ampla base de conhecimento disponível pela Internet.

\subsubsection{Simulador de WAN}

Tratando-se de ferramentas para simulação de WAN, existem várias opções disponíveis no mercado, porém, a maioria é de softwares pagos e de custo relativamente elevado, como o "Linktropy" ou "Netropy" da Apposite Technologies (APPOSITE TECHNOLOGIES, 2013, tradução nossa).

O software adotado para este trabalho é o Wide Area Network Emulator (WANem) na versão estável mais recente (2.3) no momento da avaliação. Trata-se de um software de código aberto sob Licença Pública Geral versão 2 (GPL v2), desenvolvido pelo Performance Engineering Research Centre (PERC) (WANEM, 2008). 
Figura 7: Interface web do WANem: modo avançado

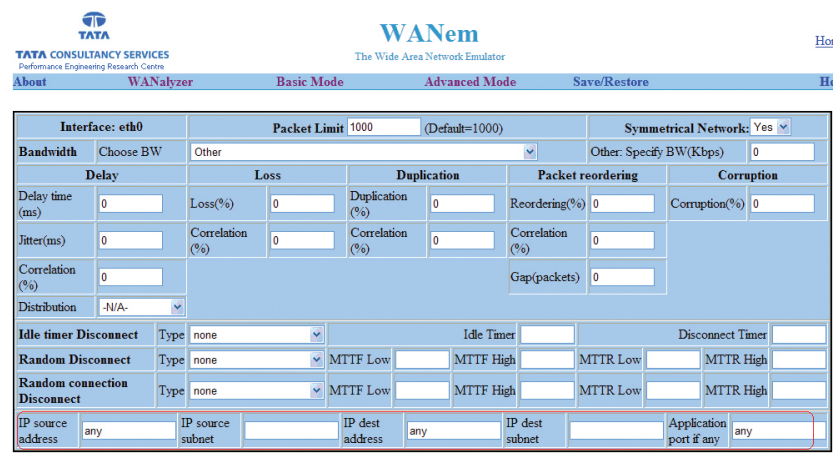

Fonte: WANEM (2008)

Conforme observa-se na Figura 7, a interface do WANem é bem intuitiva, contendo dois modos: básico e avançado. Em ambos é possível escolher vários templates pré-definidos de largura de banda, porém, o modo avançado acrescenta as configurações completas da ferramenta, incluindo: atraso, perda, duplicação, reordenação e corrupção de pacotes, além das opções de desconexão.

"WANem é um Simulador de redes de longa distância destinado a proporcionar uma experiência real de WAN/Internet, durante o desenvolvimento/testes de aplicativos em um ambiente de rede local" (WANEM ${ }^{4}, 2008$, p.1, tradução nossa).

\subsubsection{Ferramenta para testes de desempenho de rede}

Foi utilizada a ferramenta IPerf na versão 2.0.5. Trata-se de um software livre, do tipo cliente/servidor desenvolvido pela National Laboratory for Applied Network Research (NLANR). Sua principal funcionalidade é a geração de tráfego entre dois computadores, seja tráfego TCP ou UDP, proporcionando a medição da taxa de transmissão/jitter da comunicação (IPERF, 2013).

\subsubsection{Ferramenta para testes com protocolo SIP e videochamada}

Para o servidor, foi utilizado o Asterisk na versão 1.8.17.0. O Asterisk é um software gratuito e de código aberto, que implementa todas as funcionalidades de um Private Automatic Branch Exchange (PABX - central de distribuição telefônica), por meio de VoIP (ASTERISK, 2013).

Para simular os estabelecimentos de sessão/chamadas VolP, foi utilizado o SIPp na versão 3.0; software gratuito e de código aberto, que permite, entre outras funções, gerar tráfego de SIP.

\footnotetext{
${ }^{4}$ Não possui número de página por se tratar de documento eletrônico.
} 


\section{RESULTADOS E DISCUSSÃO}

Para realização dos testes, os computadores denominados no Quadro 3 como cliente e servidor, foram configurados com os IPs 192.168.0.210 e 192.168.0.230, respectivamente. No cliente, foi configurada uma rota estática, estabelecendo que para chegar ao computador servidor, devesse passar pelo simulador.

Figura 8: Topologia lógica da comunicação no laboratório de testes

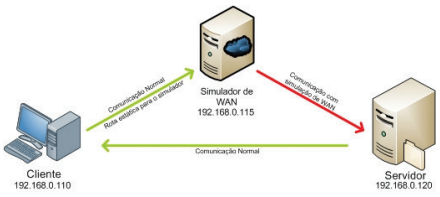

Fonte: Dos autores (2012)

Observa-se na Figura 8, a topologia lógica da comunicação deste laboratório, onde a comunicação flui normalmente (rede local) do cliente até o simulador, para, posteriormente, seguir ao servidor já com as características simuladas pelo WANem. No servidor não é configurada rota estática, portanto sua comunicação com o cliente se dá de forma direta e também flui normalmente.

Antes da alteração dos parâmetros de rede para cada teste, foi traçada uma Baseline para registrar o comportamento da comunicação sem a atuação do simulador. Lembrando que cada teste foi repetido 30 vezes e os resultados apresentam a média obtida.

\subsection{Testes básicos de rede}

Nesta etapa foram realizados 4 testes básicos de rede - atraso, perda de pacotes, largura de banda e jitter -, os quais consistiam em gerar tráfego a partir da máquina cliente até a máquina servidor, coletando os dados da comunicação. Para estes testes, os parâmetros (milissegundos de atraso/jitter, porcentagem de perda de pacotes e largura de banda) foram definidos apenas para efeitos de avaliação.

\subsubsection{Atraso}

O teste de atraso foi realizado por meio de "ping" da máquina cliente ao servidor, com limite de 10 pacotes (ping -c 10 192.168.0.230). A Figura 9 mostra as diferenças do 
RTT (round trip time - atraso de ida-e-volta) nos resultados obtidos com o simulador configurado para atrasos de 50, 100 e 200 milissegundos. Observa-se que os resultados médios obtidos corresponderam ao valor configurado no simulador.

Figura 9: Resultados dos testes de atraso

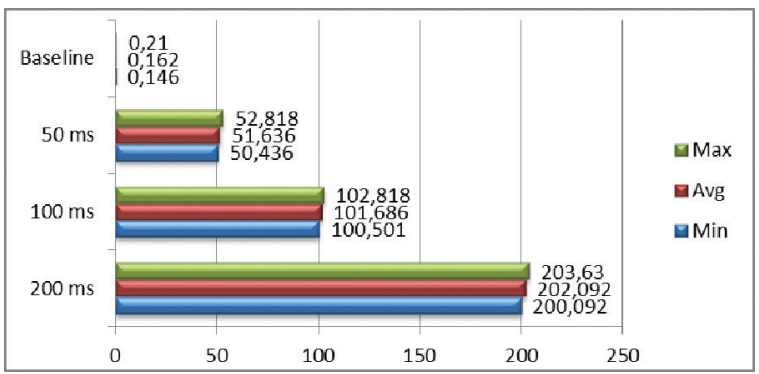

Fonte: Dos autores (2013)

\subsubsection{Perda de pacotes}

A exemplo dos testes de atraso, o de perda de pacotes foi realizado disparando "ping" com limite de 10 pacotes da máquina cliente ao servidor. A Figura 10 mostra as diferenças dos resultados obtidos para 5, 10, 20 e 30\% de perda de pacotes configurados no simulador. O gráfico demonstra que os resultados correspondem aproximadamente aos valores configurados no simulador.

Figura 10: Resultados dos testes de perda de pacotes

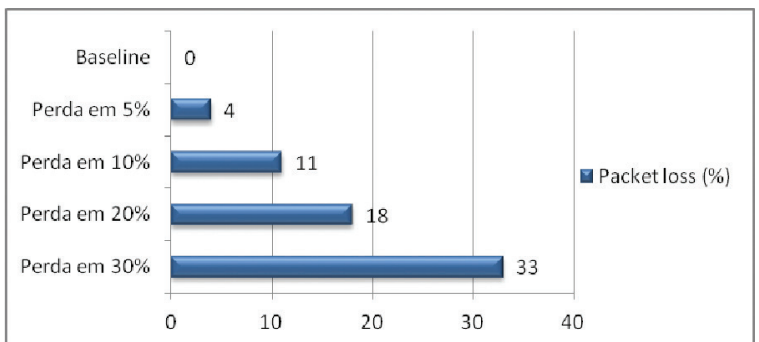

Fonte: Dos autores (2013)

\subsubsection{Largura de banda e throughput}

Para este teste, o Iperf foi configurado no modo cliente e servidor nas respectivas máquinas, lançando um fluxo TCP de uma à outra por 10 segundos. As Figuras 11 e 12 mostram os resultados para largura de banda (Mbps), e volume de "dados" transferidos (MBps): 
Figura 11: Resultados dos testes de largura de banda

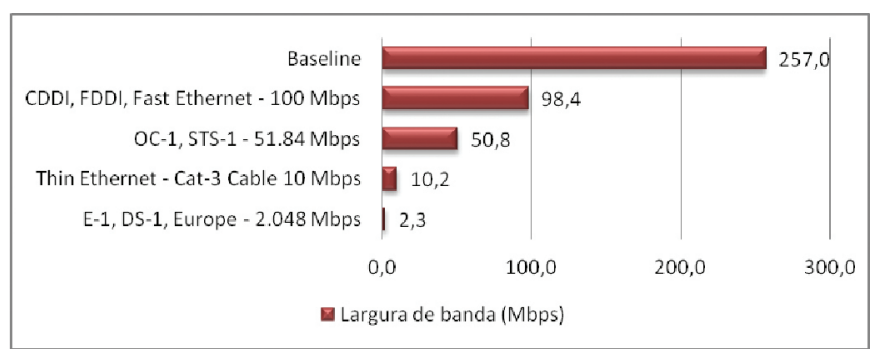

Fonte: Dos autores (2013)

Figura 12: Resultados dos testes de throughput

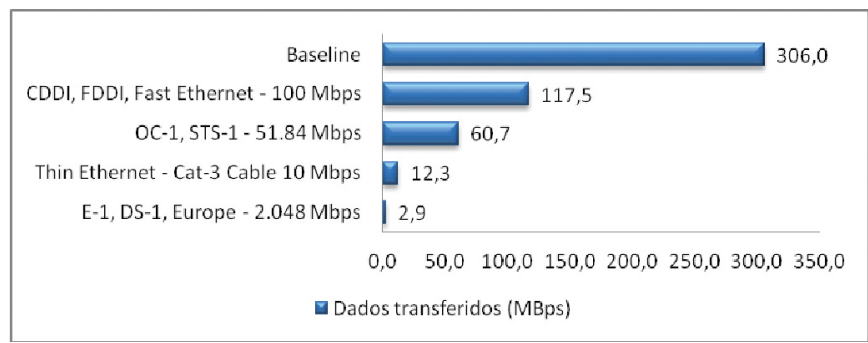

Fonte: Dos autores (2013)

Os parâmetros alterados nos testes que se encontram à esquerda dos gráficos refletem alguns dos templates de largura de banda disponíveis no WANem. Observa-se que as médias dos resultados obtidos refletem aproximadamente o valor de largura de banda configurado no WANem.

\subsubsection{Jitter}

Assim como no teste de largura de banda, no de Jitter foi utilizado o Iperf como cliente e servidor, mas desta vez gerando um tráfego UDP durante 30 segundos (Figura 13). Interessante observar a contagem de datagramas recebidos fora de ordem devido à variação no atraso. 


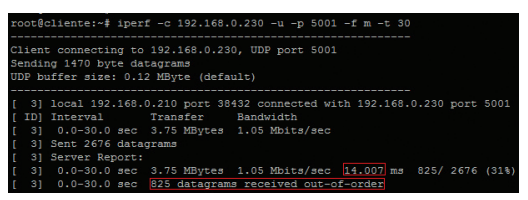

Fonte: Dos autores (2013)

A Figura 14 mostra os resultados obtidos para os testes com o Jitter configurado em 2, 5, 10 e 20 milissegundos no WANem. $O$ atraso base configurado foi de $50 \mathrm{~ms}$, sem limitação de banda.

Figura 14: Resultados dos testes de Jitter

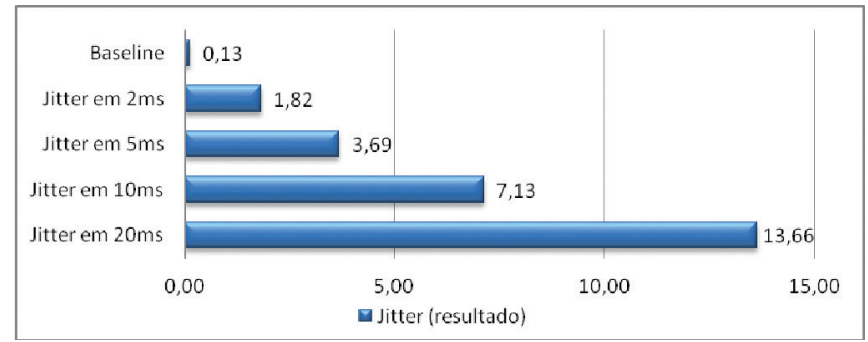

Fonte: Dos autores (2013)

Nota-se que há uma diferença nos valores configurados no simulador para os valores obtidos nos testes, permitindo concluir que a ferramenta funciona com jitter, porém, alcança valores médios aproximados, pois a variação da latência ocorre de forma aleatória dentro do valor especificado, e por isso, não apresenta valores exatos nos testes.

Como exemplo, a Figura 15 demonstra um exemplo simples de "ping" com Jitter configurado em $20 \mathrm{~ms}$ e atraso base de $50 \mathrm{~ms}$. Observa-se que a variação ocorre até aproximadamente $20 \mathrm{~ms}$ para cima ou para baixo. 
Figura 15: Saída do comando ping com Jitter em $20 \mathrm{~ms}$

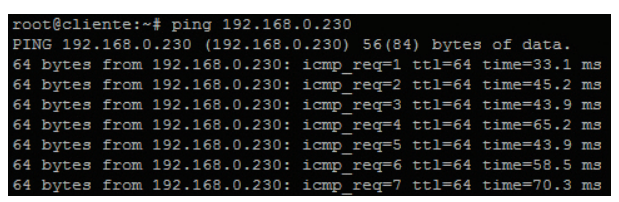

Fonte: Dos autores (2013)

\subsection{Testes com Protocolo SIP}

A maior parte das aplicações de VoIP utiliza o protocoloSIP para sinalização. A comunicação deste protocolo foca na simplicidade, já que se trata apenas de um mecanismo de controle de sessão, não interferindo nos dados trafegados. Sua arquitetura é baseada em cliente-servidor, possuindo dois componentes (GOMES, 2007):

a) User Agent Client (UAC): reside no lado do cliente, responsável por dar início às chamadas e enviar as requisições;

b) User Agent Server (UAS): reside no servidor, responsável pelas respostas das requisições feitas pelo UAC.

A troca de mensagens (requisições/respostas) do SIP é baseada em texto, semelhante ao protocolo HTTP 1.1. A Figura 16 ilustra um exemplo simples de comunicação bem sucedida, além do significado das principais mensagens envolvidas.

Figura 16: Exemplo simplificado de comunicação SIP
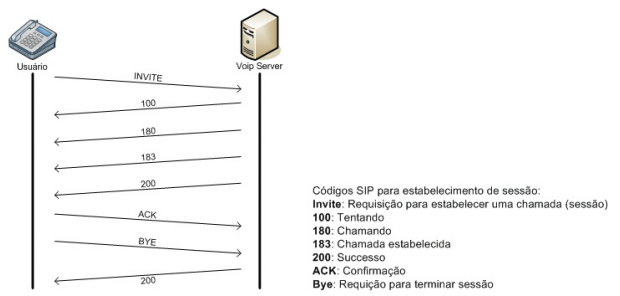

Fonte: Dos autores (2013) 
Para realização dos testes, na máquina cliente (funcionando como UAC) foi instalado o SIPp, software responsável por iniciar e terminar as sessões com o servidor VoIP, registrando os dados da comunicação. Já na máquina servidor (funcionando como UAS), foi configurado o Asterisk com uma extensão (1002), configurada para autoatendimento com um arquivo de som de demonstração do próprio Asterisk.

O teste consistiu em, a partir do cliente, disparar chamadas ao servidor. O SIPp foi configurado para disparar 20 chamadas simultâneas por vez, cada uma com duração de 10 segundos; cada teste teve duração total de 30 segundos, embora, por padrão, ele só parasse após o encerramento das últimas chamadas abertas.

Foram levados em consideração somente o atraso e perda de pacotes, já que parâmetros como Jitter e largura de banda não influenciam significantemente na sinalização do protocolo SIP.

\subsubsection{Perda de pacotes no SIP}

As Figuras 17 e 18 mostram os resultados para os testes com perda de pacotes em 30, 40,50 e $60 \%$. Estes valores foram adotados porque se percebeu nos testes que o SIP apresenta alteração de comportamento somente a partir de $30 \%$ de perda de pacotes.

Na Figura 17 observa-se a relação entre chamadas completadas e chamadas falhas. Já na Figura 18, demonstra-se a quantidade de retransmissões de Invite que o cliente precisou fazer devido aos pacotes perdidos.

Figura 17: Resultados dos testes de perda de pacotes com Protocolo SIP - Chamadas

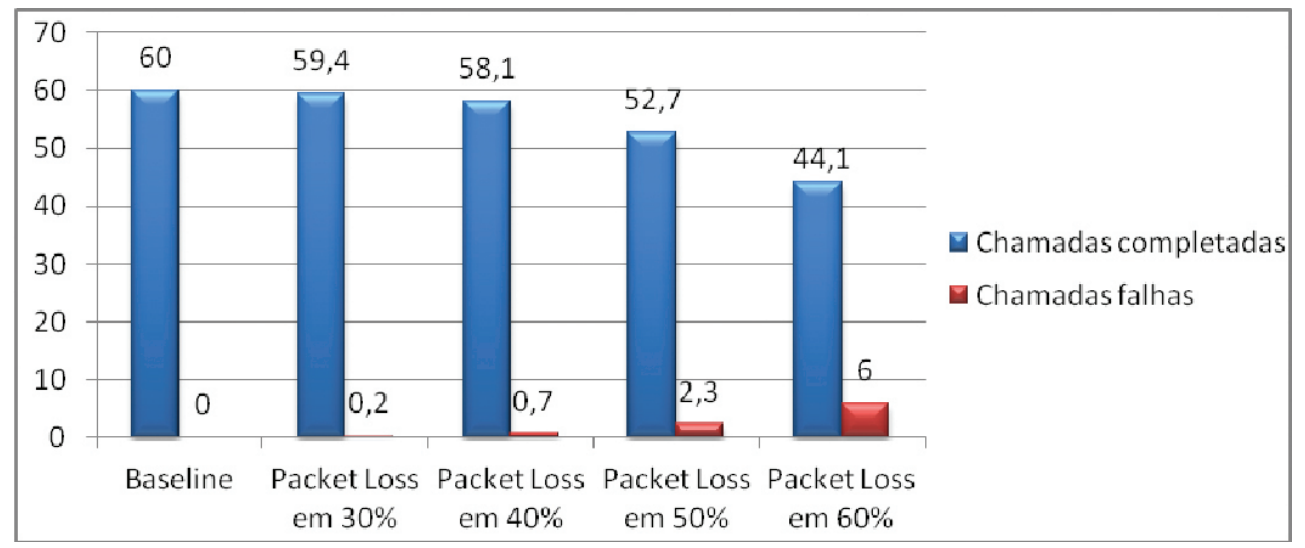

Fonte: Dos autores (2013) 
Figura 18: Resultados dos testes de perda de pacotes com Protocolo SIP - Invites

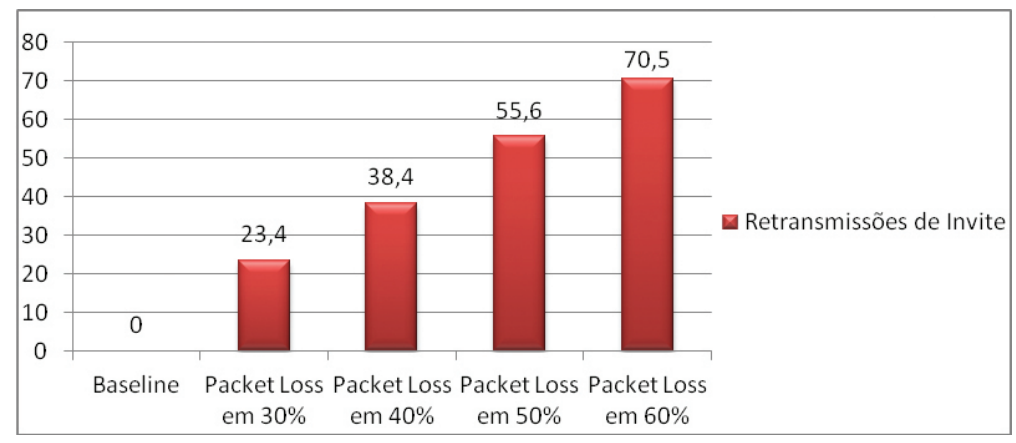

Fonte: Dos autores (2013)

Nota-se que a retransmissão de Invites aumenta gradativamente conforme se aumenta a porcentagem de pacotes perdidos. Porém, somente a partir de $30 \%$ começa a redução do número de chamadas completadas.

\subsubsection{Atraso no SIP}

As Figuras 19 e 20 mostram os resultados para os testes com atraso setado em 400, 500 e $600 \mathrm{~ms}$. Estes valores foram adotados após a percepção por meio dos testes, de que somente a partir de $500 \mathrm{~ms}$ há alteração de comportamento na comunicação do protocolo SIP.

Figura 19: Resultados dos testes de atraso com protocolo SIP - Chamadas

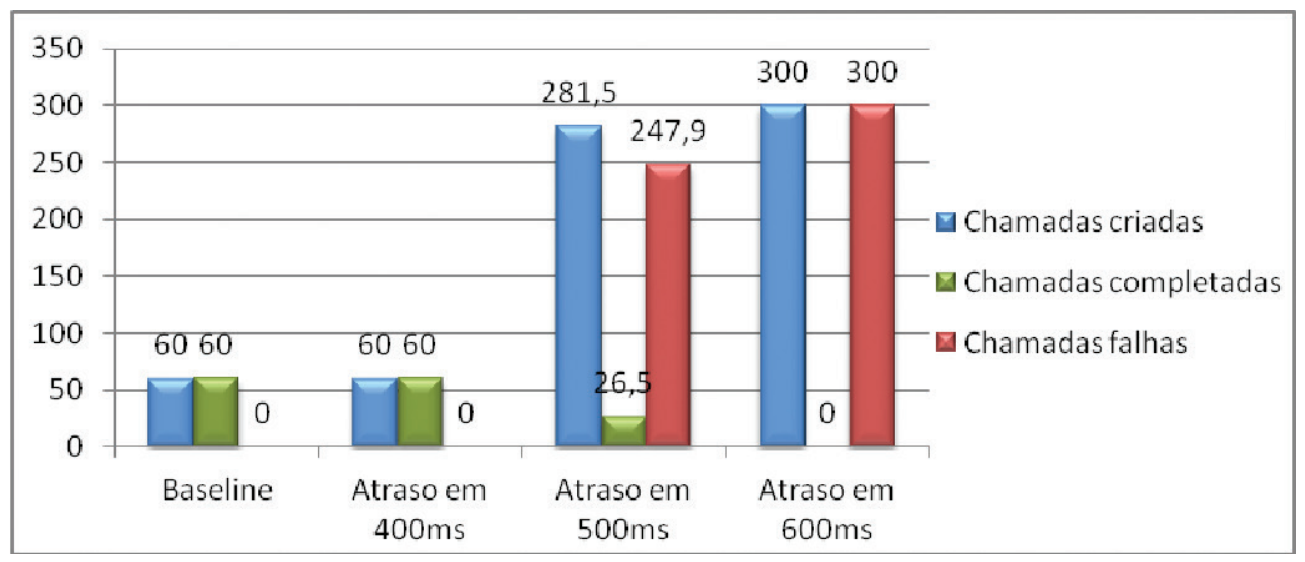

Fonte: Dos autores (2013) 
Figura 20: Resultados dos testes de atraso com protocolo SIP - Invites

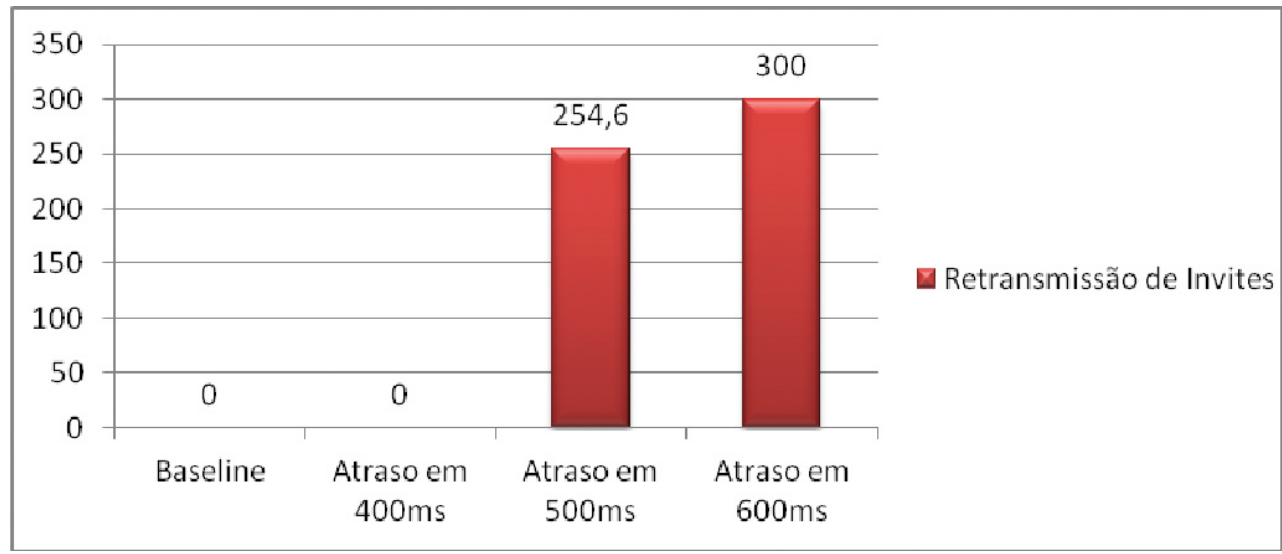

Fonte: Dos autores (2013)

Observa-se que até $400 \mathrm{~ms}$, não há alteração na comunicação. Somente a partir de $500 \mathrm{~ms}$ é que se altera o número de chamadas completadas/falhas e o protocolo SIP começa a gerar retransmissões de Invite. Já com $600 \mathrm{~ms}$, todos os Invites foram retransmitidos e todas as chamadas falharam. Isso acontece porque a retransmissão do software SIPp segue a RFC 3261, seção 17.1.2.2; quando uma mensagem SIP é enviada e nenhuma mensagem é recebida em resposta no período de $500 \mathrm{~ms}$, a mensagem SIP é reenviada.

\subsection{Testes com videochamada}

Para os testes de videochamada, foi utilizada a mesma instalação do Asterisk dos testes com SIP, mas, desta vez, com 2 extensões configuradas para permitir o tráfego $\mathrm{H} 263$ - recomendação da ITU para compressão de vídeo/ codificação para videoconferência e aplicações de videochamadas. Foram utilizados 2 videofones IP como clientes nessa comunicação.

Para simular o ambiente WAN na comunicação entre os clientes, foram configuradas 2 rotas estáticas no servidor Asterisk, estabelecendo que sua comunicação com os clientes devesse passar pelo simulador (Figura 21). 


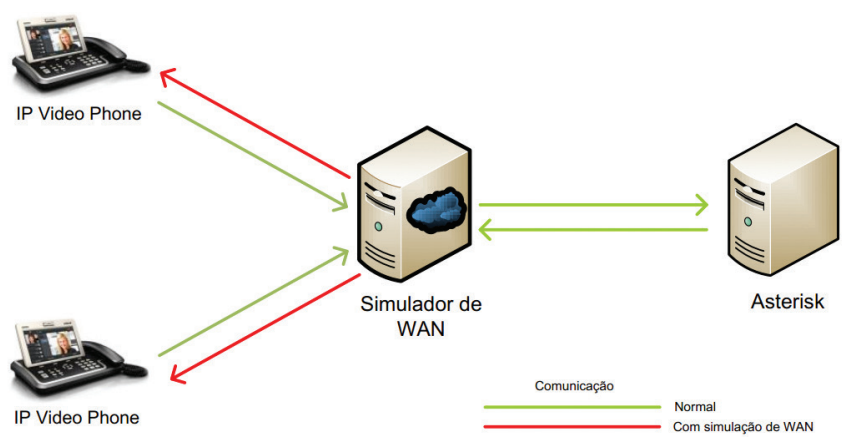

Fonte: Dos autores (2013)

O teste consistiu em efetuar chamadas entre as duas extensões, alterando os parâmetros de atraso, perda de pacotes e jitter, separadamente, na configuração do simulador, com a finalidade de perceber os impactos causados por cada um deles na videochamada.

Para avaliar a qualidade da comunicação, foi utilizado o MOS (Mean Opinion Score). Este método é comumente utilizado para determinar a qualidade de codecs e consiste da avaliação subjetiva de um grupo de pessoas a uma amostra de áudio ou vídeo. A percepção da qualidade do áudio/vídeo é então expressada em números de 1 a 5, conforme o Quadro 4 abaixo:

Quadro 4: Escala de valores do MOS

\begin{tabular}{|c|c|c|}
\hline MOS & Qualidade & Distorção \\
\hline 5 & Excelente & Imperceptivel \\
\hline 4 & Boa & Apenas perceptivel, sem incomodar \\
\hline 3 & Regular & Perceptivel, leve perturbação \\
\hline 2 & Pobre & Perturbando, mas audivel \\
\hline 1 & Ruim & Perturbando muito, inaudivel \\
\hline
\end{tabular}

Fonte: Adaptado de Hersent, Guide e Petit (2002)

Para este laboratório, foram convidados 10 participantes que, em pares, conversaram entre si, avaliando a qualidade do áudio e vídeo da videochamada para cada um dos parâmetros alterados. Ao final de cada teste, os participantes registraram suas notas de acordo com a escala MOS. As Figuras 22, 23 e 24 demonstram a média obtida para os testes de atraso, perda de pacotes e jitter, respectivamente. 
Figura 22: Resultados dos testes de atraso com videochamada

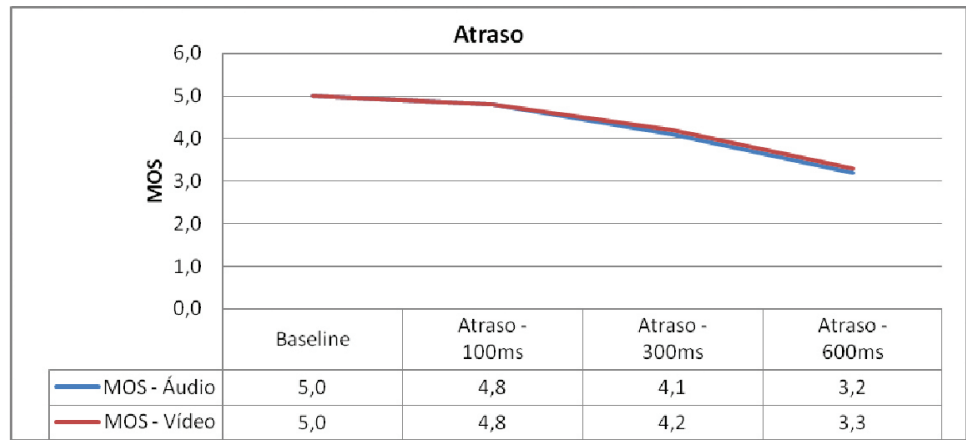

Fonte: Dos autores (2013)

Figura 23: Resultados dos testes de perda de pacotes com videochamada

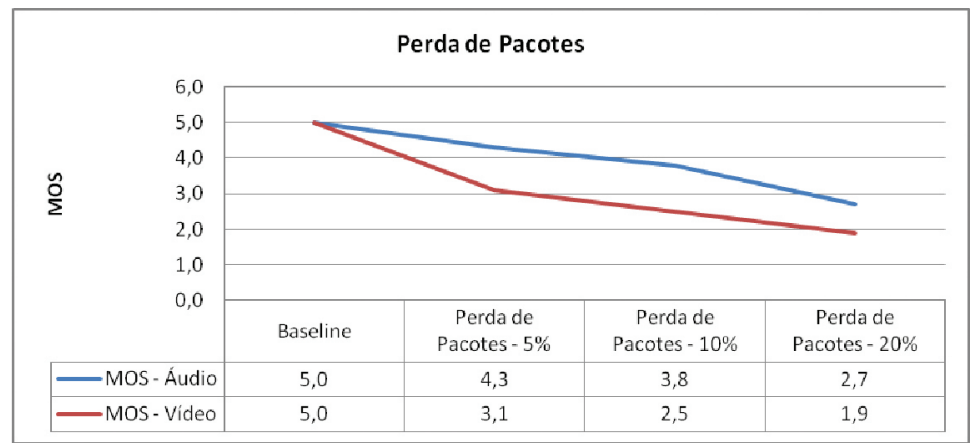

Fonte: Dos autores (2013)

Figura 24: Resultados dos testes de perda de pacotes com videochamada

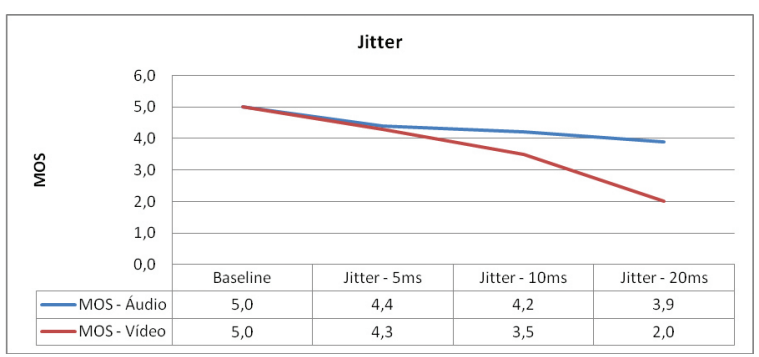

Fonte: Dos autores (2013) 
Em todos os testes, foi nítida a percepção de queda na qualidade da videochamada conforme se alteravam os parâmetros de comunicação.

\section{CONCLUSÃO}

A rede de referência virtual mostrou-se eficaz tanto nos laboratórios básicos de rede quanto nos de serviços sensíveis às características de melhor esforço da Internet. Por meio dos testes utilizando as trocas de mensagens SIP, requisições HTTP e videochamada, foi possível perceber o quanto essas características impactam na comunicação, resultando em falhas que podem prejudicar criticamente os serviços.

Apesar de pouco se ouvir falar em ambiente de WAN simulado nas empresas em geral, isso é uma prática mais comum em grandes corporações, principalmente da área de tecnologia da informação e comunicação. Segundo autores deste artigo e com base em experiência profissional , a Brasil Telecom, pertencente à Oi, por exemplo, utiliza o conceito de rede de referência virtual há quase 10 anos; antes de instalar o cabeamento e configurar os links de comunicação, a topologia/tecnologia em questão é testada em laboratório para verificar em quais condições determinados serviços de clientes (como VoIP) funcionarão satisfatoriamente, estabelecendo então requisitos mínimos, como largura de banda.

Uma das fabricantes mais conhecidas de simuladores de WAN é a Apposite Technologies. Em seu site, é possível encontrar relatos de grandes empresas à respeito de como o simulador contribuiu significativamente para o seu negócio, exemplificando as várias aplicações práticas de uma rede de referência virtual:

\footnotetext{
O emulador de WAN pagou por si, quando, em questão de dias, nós o utilizamos para replicar um link de satélite até uma plataforma de petróleo, onde um cliente estava reportando um problema de performance. Replicando o ambiente do cliente em nosso laboratório, nós rapidamente pudemos determinar que o alto atraso do link estava impedindo nosso software de utilizar a banda total disponível. Isso não só nos ajudou a evitar uma viagem dispendiosa de um desenvolvedor ou engenheiro de suporte, mas, uma vez que identificamos a causa do problema, o emulador possibilitou que validássemos a correção antes de enviarmos ao cliente. (LANDESK SOFTWARE, 2010 apud APPOSITE TECHNOLOGIES, 2013, p.1, tradução nossa)
}

A utilização de uma rede de referência virtual apresenta-se como uma ótima solução para as empresas testarem o comportamento de serviços/aplicações no "mundo real", mas sem sair de sua rede local, permitindo, além de troubleshootings diversos, agir proativamente, antecipando e tratando eventuais problemas encontrados pelos usuários. Sua implementação pode ser feita a custo muito baixo, pois não exige alto nível de especialização, os requisitos de hardware são mínimos e existem ferramentas completas, gratuitas e opensource, como o WANem, para tal. 
Os testes realizados neste trabalho tiveram um foco maior na parte de serviços e aplicações de rede. Contudo, os resultados obtidos podem motivar a elaboração de projetos voltados a testes para convergência de redes também. Cada vez mais as empresas da área de telecomunicações vêm migrando seus backbones para IP, ou seja, saindo da comutação de circuitos e integrando voz e dados com a comutação de pacotes.

Como exemplo prático, pode-se citar a migração do backhaul de uma empresa de telefonia móvel, para tecnologia IP. Conforme citado, o backhaul consiste na interligação entre o backbone e a borda da rede (no caso, as torres de telefonia). Nesse caso, a rede de referência virtual poderia ser utilizada para definir parâmetros e requisitos mínimos, para que a nova estrutura de rede atendesse satisfatoriamente à demanda dos clientes.

\title{
USING A VIRTUAL NETWORK OF REFERENCE FOR THE DEFINITION OF PARAMETERS THAT ENSURE PERFORMANCE OF SERVICES AND APPLICATIONS
}

\begin{abstract}
The development of the internet as a communication medium, coupled with ease of access, provided also the development of services available through the worldwide web. Currently, it is noted that most companies deliver some kind of service to their customers or employees through WANs or the Internet. The objective of this work is to demonstrate the benefits of using a network of virtual reference by companies, to define requirements that ensure the performance of services and applications. We have implemented a virtual reference network model using a free open-source tool for simulating WAN environment, by means of which, we tested the functionality of the tool, and some of the protocols / services used in the internet. The test results showed evidence of how the characteristics inherent to WANs or of best-effort such as the Internet, impact on communication of services / applications, proving the effectiveness of using virtual reference network.
\end{abstract}

Keywords: Networks. WAN Simulation. Software Testing. 


\section{REFERÊNCIAS}

APPOSITE TECHNOLOGIES. Testimonials. [S.I.: s.n.], 2013. Disponível em: <http://www. apposite-tech.com/customers/testimonials.html>. Acesso em: 23 maio 2013.

ASTERISK. [S.I.: s.n.], 2013. Disponível em: <http://www.asterisk.org/>. Acesso em: 23 maio 2013.

CISCO NET ACADEMY. [S.I.: s.n.], 2012. CCNA Exploration - Acessing the WAN.

Disponível em: <http://cisco.netacad.net>. Acesso em: 10 out. 2012.

COMER, Douglas E. Redes de computadores e internet. 4. ed. São Paulo: Bookman, 2007.

COSTA, Daniel Gouveia. Comunicações multimidia na internet: da teoria à prática. 1. ed. São Paulo: Ciência Moderna, 2007.

DAVIDSON, Jonathan; PETERS, James. Voice Over IP Fundamentals. 1. ed. Indianapolis: Cisco Press, 2000.

GOMES, Fábio Lúcio Soares. Videoconferência: H.323 versus SIP, 2007. Disponível em: <http://www.teleco.com.br/tutoriais/tutorialh323xsip/default.asp>. Acesso em: 23 maio 2013.

GOTTFRIED, Keren. The World of Work: Global Study of Online Employees Shows One in Five (17\%) Work from Elsewhere. [S.I.: s.n.], 2012. Disponível em: <http://www. ipsos-na.com/news-polls/pressrelease.aspx?id=5486>. Acesso em: 23 maio 2013.

HERSENT, Oliver; GUIDE, David; PETIT, Jean-Pierre. Telefonia IP: comunicação multimídia baseada em pacotes. São Paulo: Makron Books, 2002.

IPERF. The TCP/UDP Bandwidth Measurement Tool. [S.I.: s.n.], 2013. Disponível em: <http://iperf.sourceforge.net/>. Acesso em: 23 maio 2013.

KUROSE, James F.; ROSS, Keith W. Redes de computadores e a internet: uma abordagem top-down.5. ed. São Paulo: Pearson, 2010. 
PIXELBEAT. Connection speeds compared. [S.I.: s.n.], 2012. Disponível em: <http:// www.pixelbeat.org/speeds.html>. Acesso em: 23 maio 2013.

SCHULZE, Hendrik; MOCHALSKI, Klaus. Internet Study 2008/2009. [S.I.: s.n.], 2009. Disponível em: <http://www.ipoque.com/sites/default/files/mediafiles/documents/ internet-study-2008-2009.pdf>. Acesso em: 23 maio 2013.

TANENBAUM, Andrew S.; WETHERALL, David J. Redes de Computadores. 5. ed. São Paulo: Pearson Prentice Hall, 2011.

WANEM. WANem: The Wide Area Network Emulator. [S.I.: s.n.], 2008. Disponível em: <http://wanem.sourceforge.net/>. Acesso em: 23 maio 2013.

\section{SOBRE OS AUTORES}

\begin{tabular}{|l||l||}
\hline \begin{tabular}{c|} 
Dellano Lima \\
Fernandes
\end{tabular} & $\begin{array}{l}\text { Tecnólogo em Redes de Computadores graduado pelo SENAI SC. Possui } \\
\text { certificação CCNA (Cisco Certified NetworkAssociate), LPII (Linux Professional } \\
\text { Network Institute) e Itil V3 Foundation. Atualmente é Analista de Sistemas } \\
\text { na Power Solutions, atuando na administração da infraestrutura e serviços } \\
\text { de rede da Celesc Distribuição (Centrais Elétricas de Santa Catarina). }\end{array}$ \\
\hline
\end{tabular}




\begin{tabular}{|c|c|}
\hline $\begin{array}{c}\text { Douglas Dyllon } \\
\text { Jeronimo de } \\
\text { Macedo }\end{array}$ & $\begin{array}{l}\text { Graduado em Processamento de Dados pela Faculdade de Ciências } \\
\text { Administrativas e Tecnologia - FATec (2002), mestre (2008) no Programa } \\
\text { de Pós-Graduação em Engenharia de Conhecimento (PPGEGC), do } \\
\text { Departamento de Engenharia do Conhecimento (dEGC) da Universidade } \\
\text { Federal de Santa Catarina (UFSC), onde atualmente é aluno de doutorado. } \\
\text { Durante o período do doutorado, esteve atuando como pesquisador visitante } \\
\text { na The University of Western Ontario (UWO), em London, Ontario no Canadá. } \\
\text { Atua como pesquisador associado do Instituto Nacional de Convergência } \\
\text { Digital (INCoD), atuando no Laboratório de Telemedicina (LabTelemed) e } \\
\text { no Laboratório de Pesquisas em Sistemas Distribuídos (LaPeSD) da UFSC. } \\
\text { Também atua como docente na Faculdade de Tecnologia do SENAI em } \\
\text { Florianópolis. Tem experiência na área de Ciência da Computação, com } \\
\text { ênfase em Redes de Computadores, Bancos de Dados Não-Convencionais e } \\
\text { Sistemas Distribuídos. }\end{array}$ \\
\hline
\end{tabular}

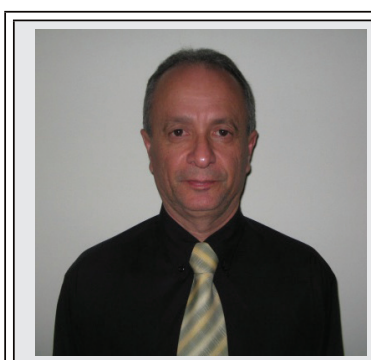

Emerson de Jesus Duarte
Atua na área de telecomunicações desde 1975. Participou do grupo de trabalho do serviço III, em sistemas de gerência, coordenado pela Telebrás durante o processo de privatização das empresas de Telecomunicações. Atuou na função de Coordenação em Comunicação de Dados de 2000 a 2009 e exerceu a função de Supervisor na área de Desempenho operacional entre 1997 e 2000. Foi responsável pela estruturação (recursos humanos, gerência, elaboração de procedimentos, análise/testes/aceitação da rede e serviços, definição de metas e indicadores) do primeiro Centro Nacional de Redes e Serviços da Brasil Telecom no DF. Exerceu a função de Coordenador de Desempenho e Segurança de Redes no CNBrt (Centro Nacional Brasil Telecom) em Florianópolis. Ministrou cursos de tecnologia PC1000 na Telebrás. Ministrou aulas de Gerência de Rede, como professor especialista, na Universidade Católica de Brasília em 2004. Tem pós-graduação em Redes e pós-graduação em Cenários e Estratégia no Ambiente das Organizações na Universidade Federal de Santa Catarina. Publicou e defendeu o artigo "Telecomunicações: A Evolução Tecnológica e a Empregabilidade do Setor" no XII SEMEAD. Elaborou o conteúdo da disciplina Serviços de Convergência do curso Técnico em Redes de Computadores-PRONATEC SENAI. Atualmente é docente no curso de Graduação em Redes e é Coordenador da Academia Cisco pela Faculdade SENAI CTAI Florianópolis, SC. 